\title{
Orientação de Monografias à distância no Programa Mídias na Educação: um processo de parceria e diálogo
}

\author{
Josete M. Zimmer ${ }^{1}$, Kassandra B. de Carvalho ${ }^{2}$, \\ 1Núcleo de Comunicação e Educação / ECA - Universidade de São Paulo (USP) \\ CEP 05508-020 - São Paulo - SP - Brasil \\ 2Núcleo de Comunicação e Educação / ECA - Universidade de São Paulo (USP) \\ CEP 05508-020 - São Paulo - SP - Brasil \\ jmzimmer@uol.com.br, kassandrabrito@htomail.com
}

\begin{abstract}
Orientation of distance-learning Monographs in the Media in Education Program: a process of dialogue and partnership

During the years 2010-2013 the NCE/ECA/USP in partnership with UFPE trained over 4000 specialists in Media in Education. Among them, 24 under our guidance. This training was through a distance-learning postgraduate course using the e-proinfo platform and open environments, functioning as communicative ecosystems. The pedagogical mediation premise was dialogicity of the subjects, formative assessment and the humanizing role of the tutor. This article brings to the discussion, memories and expectations with regard to the tutoring system and distance-learning processes of orientation of monographs in the continuing education of teachers in Media in Education conducted by the authors.
\end{abstract}

\section{Resumo}

No decorrer dos anos de 2010 a 2013, o NCE/ECA/USP em parceria com a UFPE formou mais de 4 mil especialistas em Mídias na Educação. Dentre eles, 24 sob nossa orientação. Essa formação se deu por meio de um curso de pós-graduação à distância utilizando-se a plataforma e-proinfo e ambientes abertos, funcionando como ecossistemas comunicativos. A mediação pedagógica teve como premissa a dialogicidade dos sujeitos, a avaliação formativa e o papel humanizador do tutor. Este artigo traz à discussão, memórias e expectativas quanto ao sistema de tutoria e os processos de orientação à distância de monografias na formação continuada de professores em Mídias na Educação realizados pelas autoras.

\section{Introdução}

Durante as últimas décadas, a Educação a Distância $(\mathrm{EaD})$ se diversificou e modelou cenários que antes eram apenas considerados à luz dos procedimentos de interações presenciais. Pierre Lévy (1999) já comentava sobre a antropologia do ciberespaço antes mesmo das redes sociais existirem. Nesse período, a convergência de mídias e a cultura digital foram elementos observáveis e inúmeras experiências continuam sendo desenvolvidas em EaD, principalmente no ensino superior. Não obstante, o governo 
federal em parceria com as universidades federais e estaduais vem investindo gradativamente em formação à distância, oferecendo cursos de graduação e especialização, na intencionalidade de qualificar o quadro de profissionais da educação no país. O foco dessa iniciativa é a formação de professores da educação básica sendo a UAB (Universidade Aberta do Brasil) ${ }^{1}$ e o NCE/ECA/USP (Núcleo de Comunicação e Educação da Escola de Comunicação e Artes da Universidade de São Paulo) exemplos de consolidação desse foco. Quanto às ações do NCE, sua expertise educomunicativa promoveu a elaboração de atividades e divulgação de conteúdos auxiliares, o uso de meios de interação alternativos e os instrumentos de avaliação da qualidade dos trabalhos dos cursistas e tutores. Consideramos que essas ações são iniciativas colaborativas de uma equipe coesa de pesquisadores que, em conjunto, planejaram, implementaram e avaliaram a formação à distância em Mídias na Educação dos professores da rede pública de ensino do Estado de São Paulo.

Este artigo traz à discussão memórias e expectativas quanto ao sistema de tutoria e os processos de orientação de monografias na formação continuada de professores em Mídias na Educação realizados pelas autoras. Optamos por socializar esse relato de experiência sobre algumas estratégias utilizadas e que teve efeito positivo na feitura das atividades durante a orientação das pesquisas dos cursistas, bem como os desafios encontrados. Cabe destacar que a equipe do NCE foi parceira da UFPE ${ }^{2}$ e responsabilizável por $87,54 \%$ do total de aprovados no curso. No estado de São Paulo, as duas instituições formaram $5.297^{3}$ novos especialistas em Mídias na Educação.

\section{Processo de tutoria: um diálogo afetivo e reflexivo à distância}

No curso Mídias na Educação, o processo de tutoria pode ser identificado, na forma mais original, como um conjunto de indagações e intervenções vivenciadas pelos tutores acerca da aprendizagem dos cursistas em relação à produção científica e às mídias na educação. Caberia ao tutor/orientador conhecer e aprofundar a discussão sobre as relações exercidas entre os sujeitos nas suas práticas pedagógicas, no seu cotidiano profissional e pessoal. Nesse cenário cursistas e tutores assumem uma parceria constituída pelos saberes necessários à prática cidadã à medida que o diálogo se desenvolve na solução de problemas mediados com o uso das ferramentas de comunicação interativas como fóruns, wikis, chats, Skype, SMS, ou na materialização de um produto, no caso, a produção do projeto de pesquisa ou da monografia, pois todos eles são campos de trocas afetivas, cognitivas e sociais.

Os resultados das relações entre tutor-cursista e cursista-cursista podem ser observados à luz das ideias de Paulo Freire (1970) a respeito da colaboração e da dialogicidade. Para Freire, "o diálogo é este encontro dos homens, midiatizados pelo mundo, para pronunciá-lo, não se esgotando, portanto, na relação eu-tu”. Na ação dialógica os homens ganham enquanto sujeitos, pois nessa teoria não há um sujeito que domina pela conquista de um objeto dominado. O ser humano aprende por sucessivas aproximações e distanciamentos (OKADA, 2003). E o diálogo, não impõe, não manipula não domestica, mas é sempre comunicação que funda a colaboração. A

\footnotetext{
${ }^{1} \mathrm{UAB}$ - Acesse: http://www.uab.capes.gov.br/

${ }^{2}$ UFPE - Universidade Federal de Pernambuco.

${ }^{3}$ LEÃO, I. Educomunicação na prática. Disponível em: http://espaber.uspnet.usp.br/jorusp/?p=30103
} 
dialogicidade é a essência da educação como prática da liberdade, pois é tratado como um fenômeno humano, um caminho por meio do qual os homens ganham enquanto sujeitos.

A parceria permite muito mais do que a troca de ideias ou de informações. A parceria possibilita a tessitura em conjunto. São fios condutores que se entrelaçam de modo natural, espontâneo. Trama que permite sustentação do todo sem desconsiderar as partes. (...).

A parceria permite proximidade, que por sua vez possibilita a fluidez. Fio que unem tecem e que apontam rumos para novas tessituras.

A proximidade é fundamental para o acoplamento estrutural entre as produções e os produtores do conhecimento (OKADA, 2003, p. 285).

Sabe-se que a comunicação textual em ambientes virtuais tem suas próprias características e exigências, por isso a necessidade de aprender a transitar nesses espaços se torna imprescindível para a construção do conhecimento tácito acerca dos processos de comunicação à distância (MOORE; KEARLEY, 2007). Não é rara a linha tênue entre as dúvidas expostas dos cursistas e a forma como o tutor se comunica. Seja por e-mail, ou comentários no corpo do texto das atividades, como ter a certeza de que a comunicação está sendo eficaz? Será que os feedbacks e as sugestões textuais feitas no corpo de seus textos não estariam sendo uma forma de agressão à sua produção intelectual ou pode-se compreendê-los como uma forma de co-autoria necessária à prática da elaboração monográfica e de pesquisa? Essas e outras inquietações fizeram parte da nossa prática como tutoras, e perpassaram todo o trabalho de orientação, desde a produção do projeto de pesquisa até a feitura da monografia.

\section{Para início de conversa}

Mediada pelo tutor, uma das primeiras interfaces de comunicação com o cursista no ambiente e-proinfo ${ }^{4}$ é a mensagem de abertura. Ela acontece em duas instâncias: a primeira, na abertura do módulo e a segunda, na abertura da atividade. Encaminhadas por e-mail e publicadas no ambiente, as mensagens de abertura e atividade devem conter não só as informações relevantes, mas também o "toque sutil" de um convite amigável ao cursista. Nesse momento é fundamental iniciar uma relação de parceria não só sobre o conhecimento que será consolidado, mas também das ações de troca que virão, considerando o tempo chrónos ${ }^{5}$ e kairós $^{6}$ das mediações. Nesse momento, apesar de ainda não nos fazermos suficientemente conhecidos por nossos cursistas, a abordagem escrita que usamos na abertura de um módulo, atividade ou numa simples mensagem de texto de e-mail, deve ser cuidadosamente valorizada, pois demostra em grande parte nossos atributos, quem somos, nossos valores e conhecimentos. Embora seja complexo compreender todas as características da comunicação humana, principalmente em situações onde a leitura do corpo não está presente e os timbres sonoros da voz humana não coexistem, ainda assim podemos contar com elementos submersos na linguagem escrita ou icônica e que favorecem a empatia didática.

\footnotetext{
${ }^{4}$ Ambiente virtual de aprendizagem utilizado em cursos de formação de professores ofertados pelo MEC.

${ }^{5}$ Chrónos - tempo determinado pelo cronológico.

${ }^{6}$ Kairós - tempo estabelecido pelo ritmo pessoal.
} 
Para promover a empatia didática, o tutor deve avaliar a forma de expressão que favoreça o ganho de aprendizagem, aproveitando palavras mais assertivas do seu interlocutor. A empatia didática envolve também a diversificação pela qual a mensagem deve tomar forma sugerindo uma dose de proximidade do tutor/orientador com seu cursista. Não devemos ser nem tão polidos, tampouco coloquiais, mas sensíveis que despertemos a sensação de prazer em aprender, a confiança na leitura e a segurança em seu desenvolvimento, principalmente no avanço da composição da monografia.

Nos inúmeros contatos virtuais, consideramos imprescindível para a harmonia comunicacional, fortalecer a empatia didática do tutor e a pertença do cursista, criando o clima favorável à aprendizagem. Sobre isso tutores e orientadores precisariam estar envolvidos no discurso de que:

Estudantes e professores tornam-se desincorporados nas escolas virtuais. Suas presenças precisam ser recuperadas por meio de novas linguagens, que os representem e os identifiquem para todos os demais. Linguagens que harmonizem as propostas disciplinares reincorporem virtualmente seus autores e criem um clima de comunicação, sintonia e agregação entre os participantes de um mesmo curso (KENSKI, 2004, p. 67).

Atentando-se à qualidade das mediações exercidas, a equipe de coordenação modelou um caderno de atividades com prazos definidos e orientações sobre os feedbacks e prazos de vencimento das atividades que poderiam ser reconsiderados pelo orientador à luz do chrónos e do kairós de seus orientandos. Esse instrumento, essencial à prática da $\mathrm{EaD}$, serviu não só aos tutores, mas aos cursistas orientandos que puderam ter em mãos, o modelo de avaliação, seus critérios e prazos. Sobre isso Palloff e Pratt (2004) salientam o motivo da importância de se estabelecer um prazo dos feedbacks às dúvidas e produções dos alunos (cursistas).

(...) sugerem que os professores definam claramente o tempo necessário para responder às mensagens dos alunos. Esse fator é fundamental, pois faz com que os alunos sintam o apoio do professor. Estabelecer um tempo de resposta razoável - como 24 ou 48 horas para responder a um e-mail, e 3 a 5 dias para responder a um trabalho -, e depois fazer todo o esforço possível para cumprir essa agenda ajuda os alunos a sentirem-se no caminho certo e mostra que o professor está atento (PALLOFF ; PRATT, 2004, p. 153-154).

Cabe ainda destacar que a sensação de estar junto é constituída tanto pela autopresença (como o sujeito se vê presente) quanto pela presença social (como os outros o veem). A percepção de presença e a subjetividade do cursista podem ser observadas no diálogo expresso nos fóruns, nas mensagens de correio eletrônico ou $S M S$ e diferem-se da percepção natural, ou seja, aquela realizada face a face.

É importante que nas perguntas formuladas pelo tutor, a cordialidade esteja sempre presente. Evitar termos que expressam unilateralidade de compreensão como, por exemplo, Você não compreendeu bem, reveja a página 32..., ou simplesmente, Não é isso para fazer. Num processo de comunicação, termos unilaterais tendem a dificultar a comunicação eficaz e por sua vez, criam sentimento de angústia e geram desmotivação. O aconselhável seria iniciar a frase colocando-se como portador de uma ideia que não foi bem expressa, por exemplo, (...) eu não me expressei bem..., ou, (...) 
seria interessante que aqui seja expressa a ideia central da pesquisa..., ou ainda... ficaria ótimo se...

Além disso, a receptividade e a amabilidade são requisitos essenciais de um bom tutor orientador, arriscamos ainda dizer que são partes essenciais de qualquer profissão, uma vez que o conjunto de saberes sobre os conteúdos, as técnicas e os métodos não são suficientes para garantir uma boa mediação. Desenvolver autonomia não significa aprender sozinho ou se sentir sozinho. Necessitamos de devolutivas mais significativas e humanizadas que reforcem o trabalho em parceria.

\section{O diálogo no ambiente virtual de aprendizagem}

Entre os anos de 2010 a 2013, as orientações dos cursistas para elaboração das monografias se valeram de algumas ferramentas disponibilizadas pelo ambiente virtual de aprendizagem e-proinfo. Nele as interações e a documentação das ações aconteceram de acordo com um cronograma de atividades do curso, publicado na seção "agenda' do ambiente, conforme mostra a figura 1 . O e-proinfo fez parte de um espaço coletivo de interação social e repositório de atividades dos cursistas.

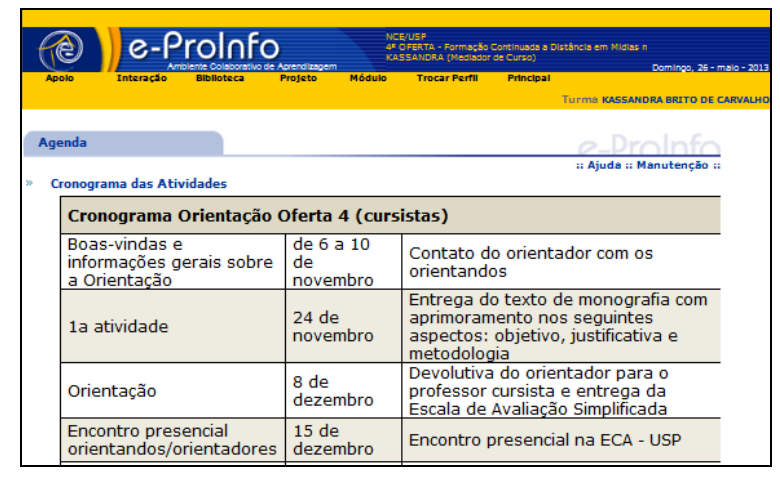

Figura 1 - cronograma de orientação

Dentre as ferramentas disponíveis no ambiente, o "fórum" foi a mais explorada. Por ser uma fase de produção individual e centrada no aluno, os fóruns foram estruturados por cursista, permitindo que cada um tivesse o seu espaço reservado com a orientação. O objetivo desse espaço era favorecer a reflexão e o diálogo sobre as fases da pesquisa e caberia ao orientador facilitar a proximidade mais humanizada entre o cursista/orientando, e o ambiente, de modo a criar a sensação de presença e atenção à aprendizagem.

Além dos fóruns individuais, havia um fórum pedagógico coletivo, criado na intencionalidade de compartilhar dúvidas e sugestões do grupo. O objetivo do diálogo nos fóruns era promover um ritual de parceria entre orientador e cursista, num movimento de intersubjetividade, conforme defende Fazenda (2002, apud Okada, 2003, p. 285), que a "intersubjetividade (princípio primeiro da parceria) é muito mais que uma questão de troca, mas que o segredo está na intenção da troca, na busca comum da transcendência". Portanto, aprendemos também, o cuidado que precisamos ter com a palavra. Esta tal como o gesto, tem por significação o mundo.

No ambiente e-proinfo, além do diálogo documentado no fórum, optou-se pela ferramenta "biblioteca do aluno" que pode ser compreendida como espaço de 
armazenamento de documentos que deveriam ser enviados para a avaliação pelo orientador. Apesar de ser um reservatório de produções, a biblioteca conta com uma ferramenta de comunicação que permite ao tutor orientador escrever as devolutivas e configurar o gerenciamento das produções enviadas pela seção de operações de configuração.

Conforme Palloff e Pratt (2004, p. 58), a aprendizagem on-line em seu melhor aspecto está centrada e focada no aluno, de modo que, quanto mais atenção os professores derem à formação de uma comunidade de aprendizagem on-line, sólida, provavelmente mais se vai conseguir atender aos alunos em suas diferentes necessidades de aprendizagem. Para as autoras é necessário que o planejamento e as atividades estejam em sintonia. Do contrário pode ocorrer um distanciamento entre o tutor e o cursista, fazendo com que o último se sinta isolado e desamparado. É neste momento que o tutor se faz presente, atuando como um elo entre a coordenação do curso, o material didático e o aluno. Além disso, é fundamental que nos feedbacks, sejamos claros e flexíveis, usando modelos informativos, auxiliando-os a irem em frente, sem dominar o diálogo ou sua produção. Sobre isso Pallof e Pratt (2004) orientam:

Quando o professor intervém em demasia, há, de fato, uma interrupção do diálogo, pois ele se torna o centro das atenções. Por outro lado, a ausência de intervenções do professor pode também interromper a discussão, pois os alunos talvez se sintam confusos e incertos sobre o que se espera deles. Atingir o equilíbrio é, então, fundamental (PALLOF ; PRATT (2004, p. 155).

A atenção dispensada ao cursista durante os momentos de construção da monografia funcionava como um catalizador da aprendizagem, aumentando também a segurança quanto às trocas e as ações da pesquisa. Portanto, caberia ao orientador investir-se de empatia didática suficiente para favorecer as necessidades de aprendizagem de cada um deles.

\section{O G-mail, o Skype e outros recursos}

O G-mail foi o gerenciador assíncrono de mensagens e de documentos socializados pela gestão do curso. Sua interface amigável e interativa permitiu controlar o fluxo de mensagens, o compartilhamento de documentos e o acompanhamento da orientação por parte da coordenação do curso. Além do G-mail, usamos com os cursistas as funcionalidades do e-proinfo com o $G$-docs ${ }^{7}$ no intuito de integrar recursos. Entretanto, esse modelo de comunicação exigiu de nós, tutores orientadores, maior controle e flexibilidade nas intervenções. Como a feitura da monografia foi realizada a partir das atividades programadas, cabia a nós tutores orientadores a gestão em cada uma delas, considerando o chrónos e o kairós para cada devolutiva, ajudando os orientandos na gestão dos conteúdos de cada atividade. Cabe ainda destacar o limite insuficiente em byte por arquivo enviado para a biblioteca do e-proinfo. Caso não contássemos com o G-mail, as produções dos cursistas deveriam ser fragmentadas, gerando retrabalho para todos e dificuldade na gestão das informações veiculadas.

\footnotetext{
${ }^{7}$ Durante a orientação o $G$-Docs integrou-se ao G-Drive.
} 
criado pelos orientandos do curso, permitindo-nos acompanhar algumas discussões acerca das dificuldades e felicidades vivenciadas por eles sobre a feitura da monografia.

\section{Avaliação, qualificação e defesa}

Durante o percurso de orientação baseamos as interpretações sobre as produções dos orientandos à luz de dois critérios: as experiências acumuladas como pesquisadoras e, os instrumentos avaliativos estabelecidos pela gestão.

Como pesquisadoras, vivenciamos diversos momentos de intervenção e adequação nos percursos da pesquisa, que possibilitou: construir um rol de conhecimentos sobre mediação e processos de elaboração de uma monografia científica bem como conhecer o universo da educação básica e as dificuldades dos professores em estabelecer diferenças entre projeto didático e projeto de pesquisa.

$\mathrm{Na}$ atuação como tutoras, o processo de avaliação foi realizado por meio de conceitos $^{8}$ elaborados pela equipe gestora do NCE/USP, com o objetivo de documentar o percurso dos orientados. Os critérios e indicadores foram elementos norteadores para atribuir valor às atividades realizadas. Outro instrumento de avaliação utilizado foram os relatórios on-line. Os links desses relatórios eram enviados pela gestão via e-mail e preenchidos num formulário do Google. Esses relatórios serviram também como instrumento de autoavaliação para as autoras desse artigo.

$\mathrm{Na}$ fase da qualificação, a monografia foi encaminhada para apreciação de um novo colaborador: o "Avaliador". Em posse dela, o avaliador tinha como responsabilidade preencher um instrumento norteador do avanço da pesquisa do orientando. Esse instrumento, chamado "Parecer", tinha como propósito descrever avanços e pontos de atenção que deveriam melhorar na monografia. Além do parecer, a qualificação foi marcada pela conferência via Skype entre as três partes envolvidas (orientando, orientador e avaliador).

Era grande a tensão e a expectativa dos orientandos quanto ao sucesso da feitura da monografia e preparo para a defesa, entretanto procuramos mitigar a ansiedade gerada compartilhando pontos de avanço e destacando a qualidade da autoria e do desenvolvimento da pesquisa observadas principalmente nos pareceres.

\section{Considerações finais}

Ao longo de todos os anos como tutoras nas quatro ofertas do curso Mídias na Educação vale dizer que mais do que orientar aprendemos com a colaboração e o compartilhamento de ideias, tanto vindas da equipe de gestão, como também, na pesquisa e atualização de temáticas que muitas vezes eram distantes da nossa área de conhecimento. Nessa perspectiva experimentamos o conceito de Crowdstorming que nos possibilitou construir coletivamente um conjunto de saberes específicos à tutoria para formação dos cursistas.

Muitas aprendizagens foram consolidadas e espaços educomunicativos construídos. Desde as primeiras orientações percebemos que os cursistas apresentavam

\footnotetext{
${ }^{8}$ PS (Plenamente Satisfatório), S (Satisfatório), M(Médio), I(Insatisfatório).
} 
dificuldades marcantes sobre o processo de se fazer pesquisa científica, o que expressa o distanciamento entre a escola e a universidade. Além do entendimento metodológico e ético e estético da pesquisa, o cursista se deparou em atender aos modelos técnicos de feitura monográficos como, a $\mathrm{ABNT}^{9}$, parafrasear, resumir, configurar o texto, editar imagens, criar tabelas e gráficos e converter arquivos que, aparentemente, pode parecer simples ações para quem está acostumado ao tratamento da informação com ambientes informatizados, mas para a maioria dos cursistas foi um grande desafio.

Sabemos que a escola e a universidade são grandes espaços de produção de conhecimento, porém os modelos de produção de conhecimento na escola ainda precisam ser mais explorados e reconhecidos. Acreditamos que o estreitamento entre a escola e a universidade, por meio de eventos, presencial ou à distância, é um ótimo começo para alicerçar a escola aos modelos científicos da pesquisa científica.

Sobre as defesas ${ }^{10}$, percebemos a evolução do cursista e o quanto o processo dialógico havia sido intenso ao ponto de que em alguns momentos era difícil mensurar claramente o quanto tínhamos interagido, distanciando-nos e aproximando-nos dos orientandos e suas pesquisas. A sensação feliz que tivemos foi a de que os momentos solidários e de interação foram maiores do que os momentos solitários. Apesar de registrar em relatórios nossas ações, não achamos importante quantificar numa escala objetiva o quanto aprendemos ou ensinamos. Entretanto, registramos nossas colaborações, pois, percebemos que socializar emoções e valores depende de construções intersubjetivas mais intensas e constantes. Se não tivéssemos laços emocionais que favorecessem a aprendizagem dos orientandos, talvez não desenvolvessem a autonomia necessária para avançar dentro de um curto período de tempo.

Compartilhando a visão de Pineau (1998) e Galvani (2002) apud Fichmann (2009), acreditamos que "a formação é uma intervenção muito complexa, profunda e global, na qual o ser e a forma são indissociáveis" e nesse período crítico, o papel mais importante que assumimos juntos aos cursistas foi o de humanizarmos o trabalho científico produzido, isto é, reconhecer no outro o valor psicológico e social do seu crescimento intelectual.

Ao final das quatro ofertas do curso, 5.297 cursistas tornaram-se especialistas em Mídias na Educação, contribuindo para promover a cultura educomunicativa em suas unidades de ensino. Salientamos que a aprendizagem decorrente das ofertas anteriores favoreceu o sucesso da última oferta do curso. Foram 4.637 cursistas orientados pela equipe do NCE, o que representa $87,54 \%$ das aprovações do curso no Estado de São Paulo.

\section{Referências}

FICHMANN, S. A educação formal básica/fundamental e a EaD. In: LITTO, F. M. ; FORMIGA, M. (Org.) Educação a Distância: o estado da arte. São Paulo : Person, 2009. P. 172-181.

\footnotetext{
${ }^{9}$ Associação Brasileira de Normas Técnicas

${ }^{10} \mathrm{O}$ curso exigia defesa presencial em banca de avaliação, composta por orientador e avaliador.
} 
FREIRE, P. Pedagogia do Oprimido (9 ${ }^{\text {a }}$ Ed). Rio de Janeiro: Paz e Terra, 1970.

KENSKI, V. M. Tecnologias e Ensino Presencial e a Distância. $2^{\text {a }}$ Ed. Campinas, São Paulo: Papirus, 2004.

LEÃO, I. Educomunicação na prática. Disponível em: http://espaber.uspnet.usp.br/jorusp/?p=30103. Acesso em: 08 jun. 2013.

LÈVY, P. A inteligência Coletiva. 2 ed. São Paulo : Edições Loyola, 1999.

MOORE e KEARSLEY. Educação a Distância: uma visão Integrada. Tradução Roberto Galman. São Paulo: Thomson Learning, 2007.

OKADA, A. L. P. Desafio para EAD: como fazer emergir a colaboração e a cooperação em ambientes virtuais de aprendizagem?. SILVA, M (Org). In: SILVA, M. (Org.). Educação online. São Paulo : Loyola, 2003. P. 273-291.

PALLOFF, R. M. e PRATT, K. O aluno Virtual: Um Guia para trabalhar com estudantes on-line. Tradução Vinicius Figueira. Porto Alegre: Artimed, 2004.

SOARES, I. O. Ecossistemas Comunicativos. Núcleo de Comunicação e Educação da ECA/USP, disponível em http://www.usp.br/nce/wcp/arq/textos/28.pdf, acessado em $18 / 06 / 2012$. 